\title{
A New Species of Glossodoris (Mollusca: Nudibranchia), of the Glossodoris atromarginata Color Group, from Indonesia ${ }^{1}$
}

\author{
Ángel Valdés ${ }^{2,3}$ and Mary fane Adams ${ }^{2}$
}

\begin{abstract}
A new species, Glossodoris tibboeli Valdés \& Adams, is described based on three specimens collected from Para Island and several others observed at Para, Kahakitang, and Mahengetang Islands, north of Sulawesi, Indonesia. The species is characterized by being starkly opaque white, with a dark brown, irregular dorsal strip extending from the rhinophores to the gill. Because of the coloration and external morphology the new species is compared with members of the Glossodoris atromarginata (Cuvier, 1804) color group, from which it differs by lacking a dark line around the mantle margin. The radulae of all members of the G. atromarginata color group are similar but differ from that of the new species in lacking rachidian teeth.
\end{abstract}

The Glossodoris atromarginata (Cuvier, 1804) color group is composed of species of dorid nudibranchs with an elongate, narrow body in which the mantle covers the foot almost completely, except for the tip of the posterior end. The mantle has a swollen appearance and is heavily undulated with permanent folds. The color is usually brown, orange, pink, or gray, with a white mantle margin. Members of this group are G. atromarginata, Glossodoris sibogae (Bergh, 1905), Glossodoris dendrobranchia Rudman, 1990, probably Glossodoris sp. A in Rudman (1986), and Glossodoris cf. atromarginata in Rudman (2002) and Carlson (2002). The systematics of members of the G. atromarginata color group has been studied in detail by Rudman (1984, 1986, 1990, 2002).

${ }^{1}$ This research is part of the National Science Foundation-supported project "Phylogenetic systematics of dorid nudibranchs," through the PEET grant DEB9978155 to Terrence M. Gosliner and A.V. The scanning electron microscope work was conducted at the facility supported by the National Science Foundation under the MRI grant DBI-0216506. Manuscript accepted 23 November 2004.

${ }^{2}$ Natural History Museum of Los Angeles County, 900 Exposition Boulevard, Los Angeles, California 90007.

${ }_{3}^{3}$ Correspondence: avaldes@nhm.org.

Pacific Science (2005), vol. 59, no. 4:603-608

(C) 2005 by University of Hawai'i Press

All rights reserved
In a recent diving trip to Indonesia M.J.A. encountered specimens of Glossodoris similar to Glossodoris atromarginata but lacking a dark line on the mantle margin and having starkly white sides and mantle margin. Anatomical examination of the specimens confirmed that they belong to an undescribed species, which is described here.

\section{MATERIALS AND METHODS}

The specimens are deposited at the Natural History Museum of Los Angeles County (LACM). Specimens were dissected by making a dorsal incision. The internal features were examined and drawn using a dissecting microscope with a camera lucida. The buccal mass was removed and dissolved in $10 \%$ sodium hydroxide until the radula was isolated from the surrounding tissue. The radula was then rinsed in water, dried, and mounted for examination with a scanning electron microscope. Features of living animals were recorded from field photographs by M.J.A.

SPECIES DESCRIPTION

Glossodoris tibboeli Valdés \& Adams, n. sp. Figures 1-3

MAterial exAmined: Holotype: Para Island, north of Sulawesi, Indonesia $\left(3^{\circ} 02.838^{\prime}\right.$ $\left.\mathrm{N}, 125^{\circ} 30.205^{\prime} \mathrm{E}\right), 10 \mathrm{~m}$ depth, 13 June 2004, 15 mm long, collected by M. J. Adams (LACM 3044). Paratypes: Para Island, north 


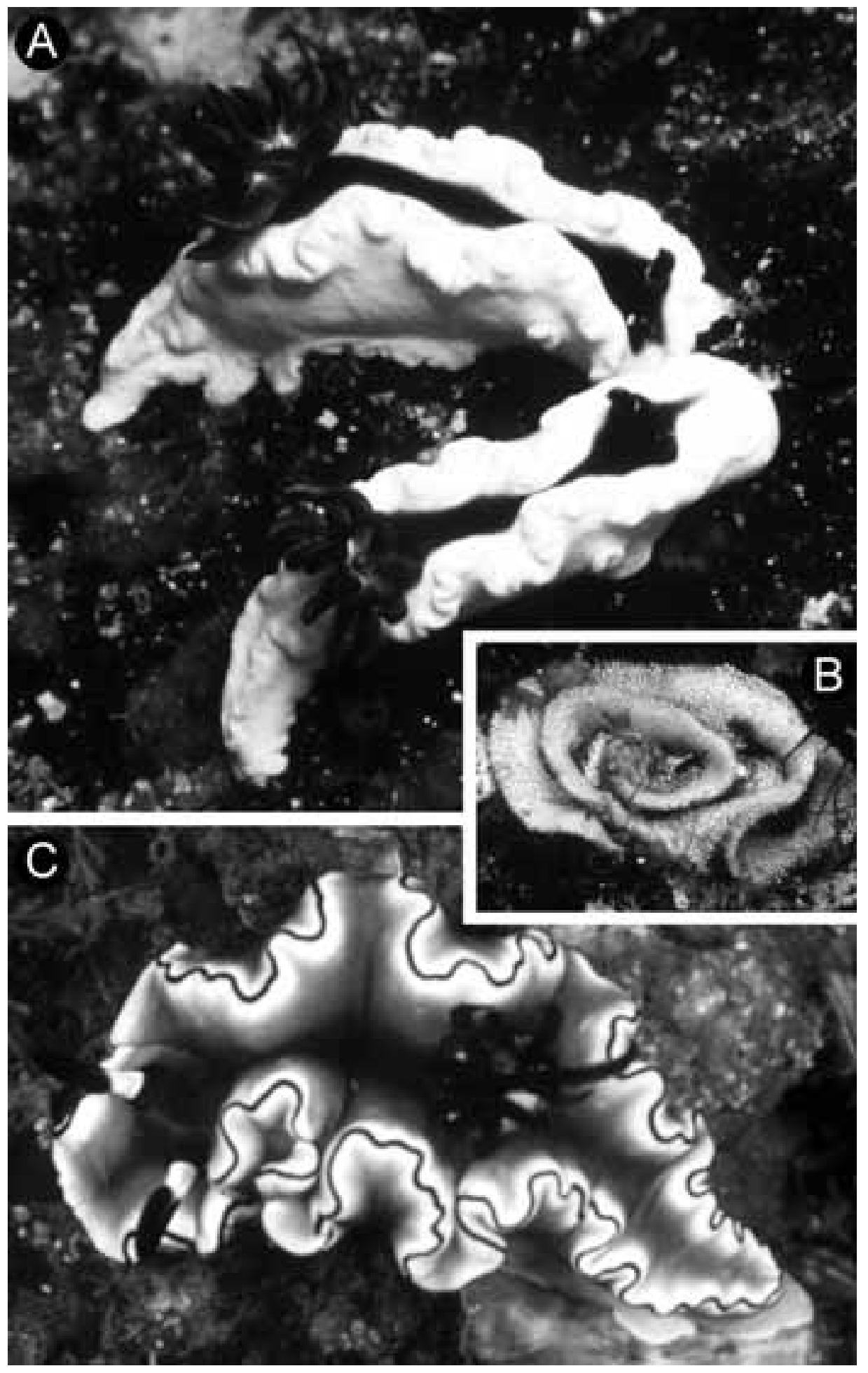

Figure 1. Living animals and egg mass. A, Glossodoris tibboeli, n. sp., holotype (LACM 3044) (top), 15 mm long, and paratype (LACM 4045) (bottom), $13 \mathrm{~mm}$ long, on their natural habitat. B, Glossodoris tibboeli, n. sp., probable egg mass, $21 \mathrm{~mm}$ maximum diameter. $C$, Glossodoris atromarginata, $19 \mathrm{~mm}$ long, specimen from northern Sulawesi on its natural habitat. All photographs by M. J. Adams. 

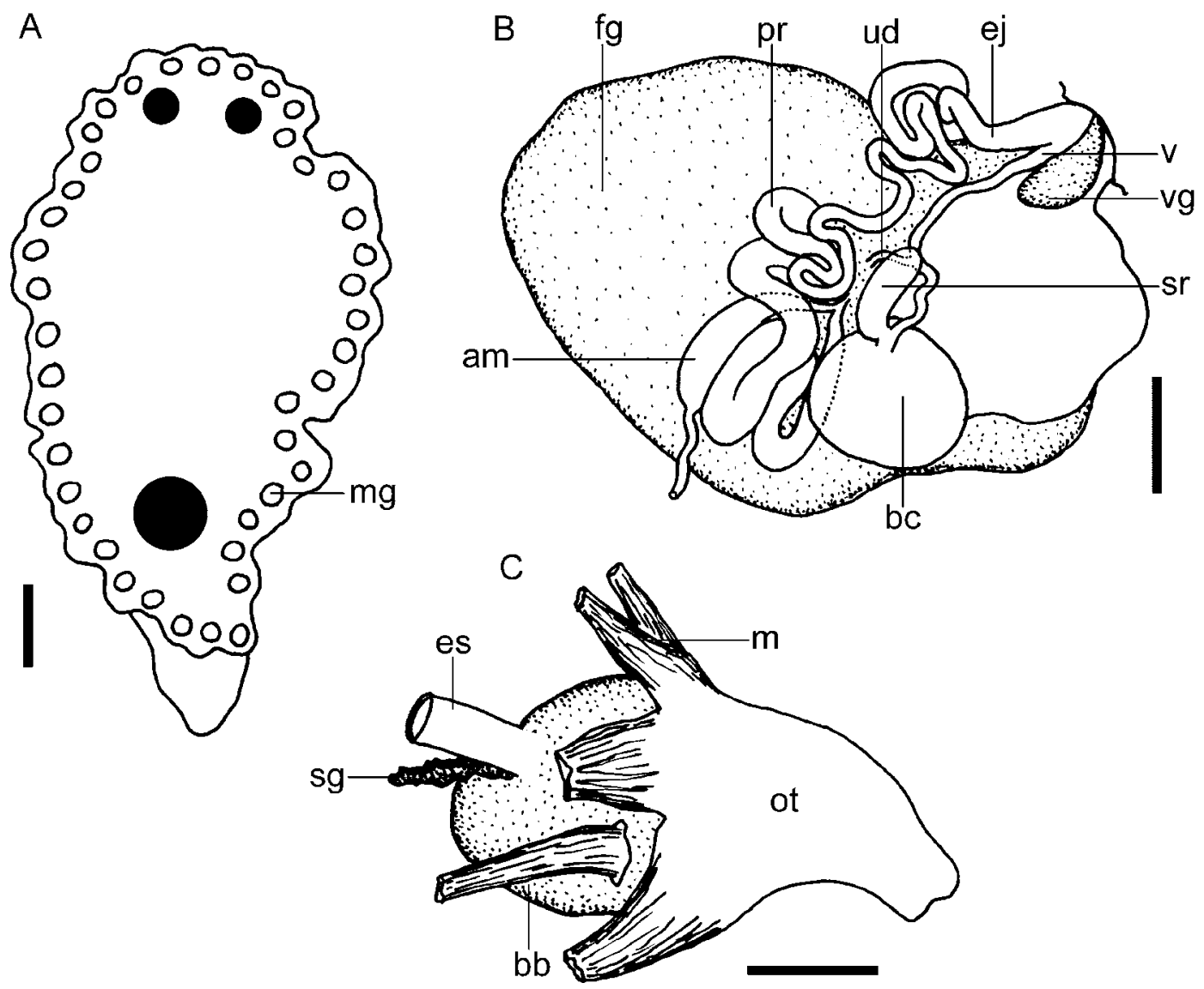

Figure 2. Glossodoris tibboeli, n. sp., paratype (LACM 3045): anatomical sketches. A, Size and arrangement of mantle glands, scale bar $=1 \mathrm{~mm} . B$, Reproductive system, scale bar $=1 \mathrm{~mm} . C$, Buccal mass, scale bar $=1 \mathrm{~mm}$. Abbreviations: am, ampulla; bb, buccal bulb; bc, bursa copulatrix; ej, ejaculatory duct; es, esophagus; fg, female glands; m, retractor muscle; mg, mantle gland; ot, oral tube; pr, prostate; sg, salivary gland; sr, seminal receptacle; ud, uterine duct; v, vagina; vg, vaginal gland.

of Sulawesi, Indonesia $\left(3^{\circ} 02.838^{\prime} \mathrm{N}, 125^{\circ}\right.$ $\left.30.205^{\prime} \mathrm{E}\right), 10 \mathrm{~m}$ depth, 13 June 2004, 2 specimens, $13-15 \mathrm{~mm}$ long, one of them dissected, collected by M. J. Adams (LACM 3045).

EXTERNAL MORPHOLOGY: Maximum size of the living animals is $15 \mathrm{~mm}$. Body is tall and elongate, with a narrow mantle margin that is thick and convoluted (Figure $1 A$ ). Behind gill, posterior section of mantle and foot merge into a relatively rigid, tapering "tail," posterior mantle edge remaining recognizable as a thick, folded ridge. Rhinophores contain 17 lamellae. Gill is composed of 13 unipinnate branchial leaves, arranged in an arc, open posteriorly, around anus. Ends of arc form an inwardly coiling spiral on each side. There is a row of subepidermal, oval mantle glands around entire mantle margin (Figure 2A).

Living animals are opaque stark white, with a dark brown band running down dorsal midline from in front of rhinophores to behind gill. The brown band is relatively narrow in the central region, then widens to encompass rhinophores and tapers to a point anteriorly. Posteriorly, band splits to encircle gill, leaving a white central patch inside gill circle. Rhinophore stalk and rachis white with a dark 
brown club. Branchial leaves and anal papilla dark brown.

ANATOMY: The buccal mass contains a large, conical oral tube with three large posterior retractor muscles attached on each side (Figure $2 C$ ). The buccal bulb is about as large as the oral tube and has a single retractor muscle attached on each side. The esophagus opens dorsally on the buccal bulb and there are two short salivary glands attached on the sides of the esophageal connection.

The radular formula is $154 \times 38.1 .38$ in the specimen examined (LACM 3045). The rachidian teeth are small, simple, triangular plates (Figure 3A). The innermost lateral teeth have long cusps with a series of 3-4 denticles on each side. The midlateral teeth have longer cusps with 3-5 denticles on the outer sides (Figure $3 B$ ). The outermost teeth are simple hooks with a single large, blunt denticle on the outer side of the cusp (Figure $3 C$ ). The jaw is composed of a number of rodlets with two cusps (Figure $3 D$ ).

The reproductive system is triaulic (Figure $2 B)$. The ampulla is large, simple, with no folds, and narrows into a short postampullary duct that connects to the female glands and the prostate. The prostate is convoluted, relatively long, and connects to a long, narrow deferent duct that expands into a wider, muscular ejaculatory portion. The vagina is long and narrow and connects to the bursa copulatrix. The bean-shaped seminal receptacle is about one-third as large as the bursa copulatrix and connects to the vagina immediately before its insertion into the bursa copulatrix. A short, thin uterine duct connects to the vagina at its proximal one-third. The penis is smooth.

NATURAL history: The specimens were collected from a group of 12 identical animals clustered on a round, brown reef sponge at a depth of $10 \mathrm{~m}$. None of them was laying eggs or mating; however, three egg masses (Figure $1 B$ ) were observed on or immediately adjacent to the sponge and most likely belong to these animals. The egg mass is a ribbon containing numerous white eggs about $200 \mu \mathrm{m}$ in diameter, indicating that this species is most likely a direct developer.

Several other specimens were observed but not collected, at Para, Kahakitang, and Mahengetang Islands, north of Sulawesi, Indonesia, by Mark Strickland and Hans Tibboel.

ETymology: This species is dedicated to Hans Tibboel, who found the specimens and brought them to our attention.

\section{DISCUSSION}

Glossodoris tibboeli is clearly different from other species of the genus Glossodoris Ehrenberg, 1831, in external coloration and internal anatomy. The most similar species is Glossodoris atromarginata, which is also an elongate species with a white mantle margin and a brownish area in the center of the dorsum (Rudman 1984, 1986). However, G. atromarginata has a dark line around the mantle margin that is absent in G. tibboeli. The body color of $G$. atromarginata varies from creamy white to pale brown. Specimens from northern Sulawesi, Indonesia, consistently show the dark line around the mantle margin and a pale brown coloration (Figure 1C; M.J.A., pers. obs.). In specimens of $G$. atromarginata that are most similar to G. tibboeli, the dark area in the center of the mantle gradually fades all the way to the lateral border, whereas in G. tibboeli the central brown strip ends abruptly just before the mantle folds begin. In G. tibboeli the mantle border folds are fewer in number and less pronounced than in G. atromarginata.

Internally, these two species are distinguishable by the morphology of the reproductive system. The seminal receptacle of G. atromarginata is proportionally larger in relation to the bursa copulatrix than that of G. tibboeli. Also, the seminal receptacle of $G$. atromarginata connects directly into the bursa copulatrix (Rudman 1984), whereas in G. tibboeli it connects to the vagina. In the digestive system, G. atromarginata has an oral tube 810 times larger than the buccal bulb (Rudman 1984, 1986), whereas in G. tibboeli the oral tube is approximately as large as the buccal bulb. The radula of these two species is very similar, but $G$. tibboeli has small rachidian teeth, which are absent in G. atromarginata.

Rudman (2002) and Carlson (2002) described what could be a color variation of $G$. 

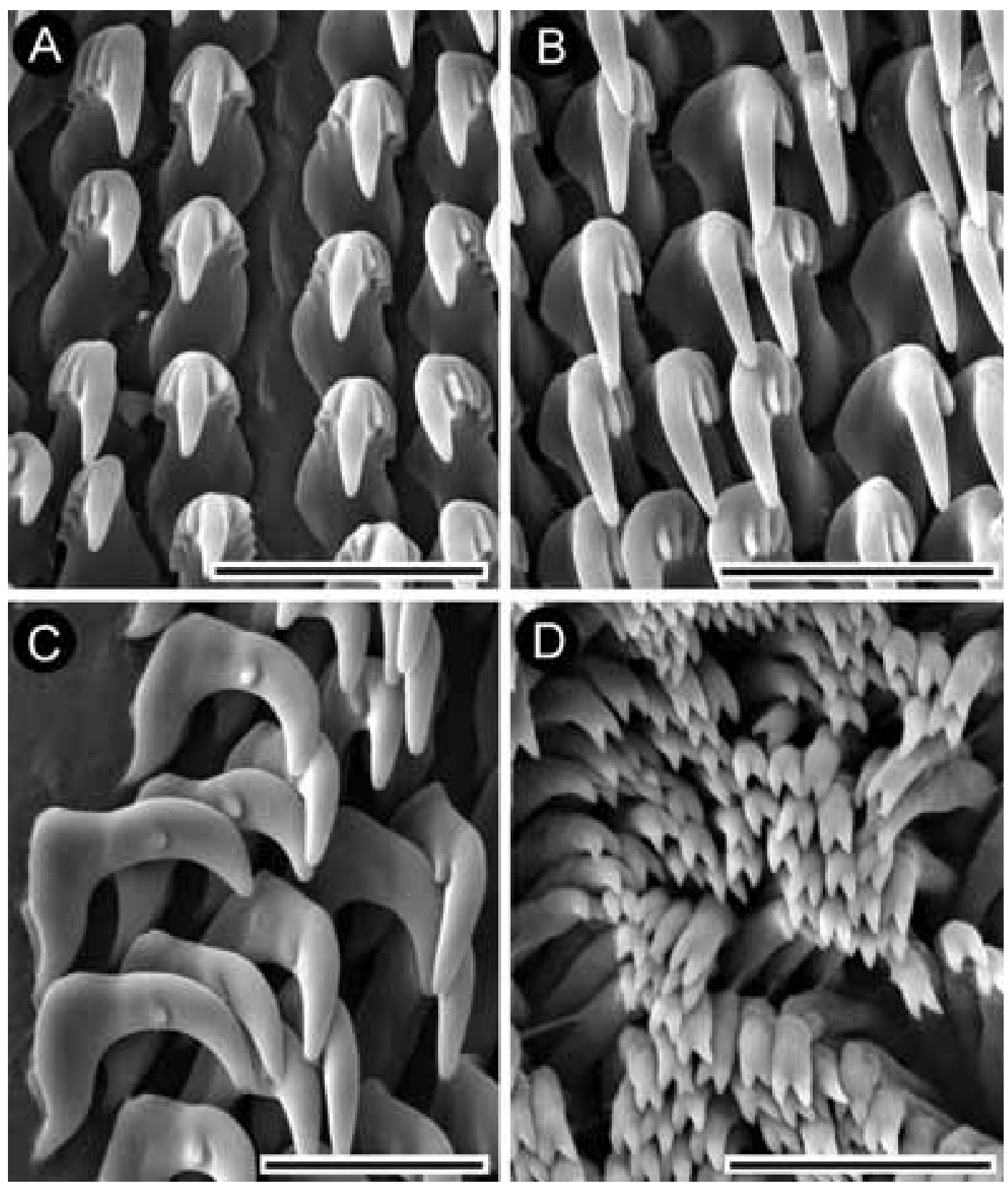

FiguRe 3. Glossodoris tibboeli, n. sp., paratype (LACM 3045): scanning electron micrographs of radula and jaws. $A$, Rachidian and inner lateral teeth, scale $\mathrm{bar}=30 \mu \mathrm{m} . B$, Midlateral teeth, scale bar $=30 \mu \mathrm{m}$. $C$, Outer lateral teeth, scale bar $=20 \mu \mathrm{m}$. $D$, Jaw elements, scale bar $=30 \mu \mathrm{m}$. 
atromarginata, or a different, undescribed species, lacking a dark line on the mantle margin. Animals with that coloration (referred to as Glossodoris cf. atromarginata) were collected only from Guam and Saipan. The anatomy of these specimens is unknown, but they differ from $G$. tibboeli by having a dirty white mantle margin and pale brown dorsum and body sides, instead of pure white body sides and mantle margin and dark brown center on the dorsum.

Glossodoris dendrobranchia is another species with coloration similar to that of G. tibboeli. It is characterized by a brown body with a whitish mantle border and branched branchial leaves, for which it was named. However, G. dendrobranchia is easily distinguishable by having pure white rhinophores and gill. The radula of $G$. dendrobranchia as described by Rudman (1990) has alternating complete and incomplete transverse rows of teeth, which he considered to be aberrant. The morphology of the radular teeth is very similar to those of G. atromarginata and G. tibboeli, but G. dendrobranchia lacks rachidian teeth (present in G. tibboeli) and the two or three outermost teeth are more elongate and lack the denticle present in both $G$. atromarginata and $G$. tibboeli. In addition, the oral tube of $G$. dendrobranchia is six times as large as the buccal bulb, whereas in G. tibboeli these two structures are about the same size. The reproductive system of the holotype of $G$. dendrobranchia is immature so it cannot be compared with that of G. tibboeli.

Another species belonging to the same chromatic group is Glossodoris sibogae, which is known only from Indonesia, Fiji, and French Polynesia. This species is similar in shape and color to G. tibboeli, but it has an orange background color and a wide black line around the mantle margin (Rudman 1986). The radula of $G$. sibogae is very similar to those of G. atromarginata, G. dendrobranchia, and G. tibboeli, and it appears to have rachidian teeth as in G. tibboeli (Rudman 1996: figs. $6 A-B, 7 A$ ). However, the two outermost teeth of $G$. sibogae lack denticles, whereas in G. tibboeli these teeth have a large, blunt denticle.

Finally, Glossodoris sp. A, described in Rudman (1986), has a body shape similar to those of other members of the G. atromarginata color group, but it is easily distinguishable from G. tibboeli by having a uniform pink coloration. Glossodoris sp. A is the only member of the G. atromarginata color group that has a clearly distinct radula, with curved, multidenticulate outermost teeth.

\section{ACKNOWLEDGMENTS}

We are indebted to Hans Tibboel, who found the new species for the first time and brought it to our attention. He and Mark Strickland accompanied M.J.A. during the expedition in which the specimens were collected.

\section{Literature Cited}

Carlson, C. 2002. Glossodoris cf. atromarginata from Guam. Sea Slug Forum, available at www.seaslugforum.net/find.cfm?id= 7387 (29 June).

Rudman, W. B. 1984. The Chromodorididae (Opisthobranchia: Mollusca) of the IndoWest Pacific: A review of the genera. Zool. J. Linn. Soc. 81:115-273.

1986. The Chromodorididae (Opisthobranchia: Mollusca) of the IndoWest Pacific: The genus Glossodoris Ehrenberg[h] (= Casella, H. \& A. Adams). Zool. J. Linn. Soc. 86:101-184.

- 1990. The Chromodorididae (Opisthobranchia: Mollusca) of the Indo-West Pacific: Further species of Glossodoris, Thorunna and the Chromodoris aureomarginata colour group. Zool. J. Linn. Soc. 100:263-326.

2002. Glossodoris cf. atromarginata. Sea Slug Forum, available at www.seaslugforum.net/gloscfatro.htm (25 June). 